\title{
Expression of pyruvate carboxylase in cultured human astrocytoma, glioblastoma and neuroblastoma cells
}

\author{
Eduard Gondášํ, Alžbeta Králová Trančíková, Zuzana Majerčíková1, Michal Pokusa², \\ Eva Baranovičová ${ }^{2}$, Peter Bystrický ${ }^{2}$, Dušan Dobrota ${ }^{1}$ and Radovan Murín ${ }^{1}$ \\ ${ }^{1}$ Department of Medical Biochemistry, Jessenius Faculty of Medicine in Martin, Comenius University in Bratislava, Martin, \\ Slovakia \\ ${ }^{2}$ Biomedical Center Martin, Jessenius Faculty of Medicine in Martin, Comenius University in Bratislava, Martin, Slovakia
}

\begin{abstract}
Pyruvate carboxylase (PC) is an enzyme catalyzing the conversion of pyruvate to oxaloacetate, which possesses anaplerotic role in cellular metabolism. The expression of PC was confirmed in cells of several cancer types, in which it ensures several cellular functions, such as growth and division. To investigate the expression of PC in human astrocytoma, glioblastoma and neuroblastoma cells we applied the immunodetection methods. The results of the Western blot analysis and immunocytochemical detection revealed the presence of PC in human astrocytoma, glioblastoma and neuroblastoma cells. Furthermore, application of PC inhibitor, 3-chloro-1,2-dihydroxypropane (CDP), negatively impacts the viability of astrocytoma cells. The cytotoxic effect of CDP could be partially reversed by application of citrate, 2-oxoglutarate and malate in incubation media. Our results revealed that astrocytoma, glioblastoma and neuroblastoma cells are equipped with PC, which might significantly contribute by its anaplerotic activity to sustain the metabolism of cancer cells.
\end{abstract}

Key words: Cancer metabolism - Pyruvate carboxylase - Astrocytoma - Glioblastoma - Neuroblastoma

\begin{abstract}
Abbreviations: BSA, bovine serum albumin; CAC, citric acid cycle; CDP, 3-chloro-1,2-dihydroxypropane; DMEM, Dulbecco's modified Eagle's medium; EDTA, ethylenediaminetetraacetic acid; FBS, fetal bovine serum; NHA, normal human astrocyte; PBS, phosphate-buffered saline; PC, pyruvate carboxylase; TBS, Tris-buffered saline.
\end{abstract}

\section{Introduction}

The autonomous growth stimulation and resistance to cell growth inhibitory signals belong to characteristic features of cancer cells (Hanahan and Weinberg 2000, 2011). These two features are closely associated with the transformation of cellular metabolism, resulting in a promotion of its anabolic part with a biosynthetic capacity (Locasale and Cantley 2011). Cancer cellular anabolism is also the subject to the availability of substrates. The substrates, essential for the synthesis of macromolecular substances either originate from the extra-

Correspondance to: Radovan Murín, Department of Medical Biochemistry, Jessenius Faculty of Medicine in Martin, Comenius University in Bratislava, 03601 Martin, Slovakia

E-mail: murin@jfmed.uniba.sk cellular space or are withdrawn from intermediate cellular metabolism. Indeed, several intermediates from the citric acid cycle (CAC) has a role of the precursors for biosynthesis of the non-essential amino acids, nucleotides and membrane constituting compounds (Danhier et al. 2017). To compensate for a loss of withdrawn CAC intermediates by cataplerotic processes and to avoid the cellular metabolic collapse, the cells should replenish the CAC by anaplerotic reactions (Owen et al. 2002; Jitrapakdee et al. 2006; Lao-On et al. 2018).

Anaplerotic metabolism involves the processes of formation of 2-oxoglutarate, oxaloacetate and succinyl-CoA, which are formed by catabolism of glucogenic amino acids and oddchain fatty acids, or enzymatic carboxylation of pyruvate to oxaloacetate by pyruvate carboxylase (PC) (Jitrapakdee et al. 2006; Lao-On et al. 2018). In the metabolism of several types of cancer cells, glutamine metabolism is considered to contribute 
significantly to 2-oxoglutarate generation. Besides, glutaminolysis provides the cells with reduced nitrogen, which is essential for the biosynthesis of nitrogen bases and non-essential amino acids (Altman et al. 2016; Cluntun et al. 2017). However, decreased glutaminolysis activity of the cancer cells could be compensated or even replaced by a PC response (Cheng et al. 2011; Sellers et al. 2015; Lao-On et al. 2018). Furthermore, the inhibition of PC activity correlates with decreased metabolic activities of cancer cells, as well as their growth and migration capability (Caneba et al. 2012; Sellers et al. 2015; Christen et al. 2016; Phannasil et al. 2017; Lin et al. 2020). The expression of PC has already been confirmed in the cancer cells of the mammary gland, ovarian (Caneba et al. 2012) and lung tumours (Sellers et al. 2015), myeloid leukaemia (Pate et al. 2014) as well as glioblastoma cell lines (Cheng et al. 2011).

Due to, PC possesses the supportive role for the growth, division and migration of the cancer cells (Lao-On et al. 2018) and could provide a therapeutic target to prevent cancer progression (Lin et al. 2020), the knowledge about its expression among different cancer types might be beneficial. Hence, by the immunocytochemical method, we investigated the expression of PC in cultured human astrocytoma, glioblastoma and neuroblastoma cells, and besides, we tested the importance of the enzymatic function of PC for sustaining the viability of astrocytoma cells.

\section{Materials and Methods}

\section{Cell cultures}

All tested human types of cells were obtained from commercial sources and incubated under the recommended conditions. Briefly, human astrocytes were obtained from Gibco and grown in medium provided by a supplier. The cells in human neuroblastoma cell line SH-SY5Y (ATCCCRL-2266) were cultured in Dulbecco's modified Eagle's medium (DMEM)/Nutrient Mixture F-12 Ham (Sigma, D8437) supplemented with $10 \%$ (v/v) fetal bovine serum (FBS), penicillin $(100 \mathrm{U} / \mathrm{ml})$ and streptomycin sulphate $(0.1 \mathrm{mg} / \mathrm{ml})$. Cells in human glioblastoma cell line A172 (ATCC-CRL-1620) and astrocytoma cell line SW1088 (ATCC-HTB-12) were cultured in DMEM-high glucose (Sigma, D6429) supplemented with 10\% (v/v) FBS, penicillin $(100 \mathrm{U} / \mathrm{ml})$ and streptomycin sulphate $(0.1 \mathrm{mg} / \mathrm{ml})$.

The cells were kept in a humidified incubator in an atmosphere enriched to $5 \% \mathrm{CO}_{2}$ at $37^{\circ} \mathrm{C}$. The plastic culture wells and dishes were obtained from Sigma.

\section{Immunoblotting analysis}

The cells were twice rinsed with ice-cold phosphate-buffered saline (PBS) and subsequently lysed in hypotonic solution
(100 mmol/l Tris/HCl, pH 7.4, $1 \mathrm{mmol} / \mathrm{l}$ EDTA). The cell lysates were clarified by centrifugation $\left(10,000 \times g, 4^{\circ} \mathrm{C}\right.$, $5 \mathrm{~min}$ ) and produced supernatants were used for protein estimation by Bradford's method and subsequently for immunoblotting analysis. Before the electroblotting on the nitrocellulose membrane (Bio-Rad Laboratories), the proteins $(10 \mu \mathrm{g} / \mathrm{lane})$ were separated in $10 \%$ acrylamide gels by SDS-PAGE method. To detect the presence of pyruvate carboxylase among the separated proteins, the membranes were incubated with the rabbit antiserum diluted 1:500 in Trisbuffered saline (TBS) supplemented with $0.05 \%$ Tween-20 and $1 \mathrm{mg} / \mathrm{ml}$ bovine serum albumin (BSA) at $4^{\circ} \mathrm{C}$ for $12 \mathrm{~h}$, followed by the incubation with affinity-purified anti-rabbit IgG conjugated with horse-radish peroxidase. Generation of the chemiluminescent signal was initiated by addition of the SuperSignal West Pico Chemiluminescent Substrate solution (Thermo-Scientific) and recorded by Chemidoc XRS system (Bio-Rad Laboratories). To normalize the chemiluminescent signal of $\mathrm{PC}$ to $\beta$-actin, the membranes were stripped and subsequently re-stained with mouse monoclonal anti- $\beta$-actin antibodies followed by anti-mouse IgG molecules conjugated with horse-radish peroxidase. The obtained chemiluminescent signals for PC and $\beta$-actin were quantified (Image Studio ${ }^{\mathrm{TM}}$ Software, LI-COR, Inc.) and the relative expression level of PC to $\beta$-actin in different cell types was calculated and normalized against the relative expression level of PC in normal human astrocytes (NHA).

\section{Immunofluorescent double staining}

Before the experiment, the cells were plated into culture 6 -well plates with attached glass coverslips $(20 \times 20 \mathrm{~mm})$ at the bottom. After 48-hour incubation, the cells were washed twice with ice-cold PBS and subsequently fixed with freshly prepared paraformaldehyde $(4 \% \mathrm{w} / \mathrm{w})$ solution in PBS for $10 \mathrm{~min}$. The paraformaldehyde solution was discarded from fixed cells and the cells were permeabilized with TBS supplemented with $0.3 \%$ (w/w) Triton X-100 (Sigma). Subsequently, the mixture of primary antibodies, rabbit anti-PC (Cesar and Hamprecht 1995; Murín et al. 2009) and human anti-pyruvate dehydrogenase (Murín et al. 2009), was prepared by diluting both antibodies in ratio 1:250 with the solution consisting of TBS supplemented with $0.1 \%(\mathrm{w} / \mathrm{w})$ Triton X-100 and $1 \mathrm{mg} / \mathrm{ml}$ bovine serum albumin, of which $200 \mu \mathrm{l}$ were layered on the fixed cells containing surface of the coverslip. After the overnight incubation at $4^{\circ} \mathrm{C}$, the antiserum containing solution was discarded and the cells were washed three times for $5 \mathrm{~min}$ in TBS solution supplemented with $0.1 \%(\mathrm{w} / \mathrm{w})$ Triton X-100. The mixture of applied secondary antibodies contained mouse anti-rabbit IgG molecules conjugated with Alexa Fluor 488 and mouse anti-human IgG conjugated with TRITC, which were diluted 1:500 in Tris-buffered saline supplemented with $1 \mathrm{mg} / \mathrm{ml}$ 
of BSA and $0.1 \%$ Triton X-100 and incubated with the cells at room temperature for $1 \mathrm{~h}$. After discarding the solution with secondary antibodies, the cells were washed in TBS $(3 \times 5 \mathrm{~min})$ and subsequently mounted with the DAPI containing solidifying mounting medium (Sigma).

The fluorescence was observed and photomicrographs were taken by a Carl Zeiss Axio Imager 2 imaging system equipped with an Apotome detector (Carl Zeiss AG, Jena, Germany) and an HXP 120V fluorescence source. All fluorescence images were obtained using relevant light filters, a Plan Apochromat $60 \times / 1.4$ Oil DIC objective with the size of the field of view of $148.03 \times 110.91 \mu \mathrm{m}$ and a resolution of $1388 \times 1040$ pixels. The maximum intensity projection of z-stacks composed of 4-6 focal planes with a total thickness of $5 \mu \mathrm{m}$, as well as the final editing of images took place in the ZEN BLUE software.

\section{Cellular viability test}

An MTT assay was performed to assess cellular viability (Mosman 1983). Adherent astrocytoma cells (SW1088, ATCC) seeded in triplicates in 96-well flat-bottomed plates at density 10000 cells/well were preincubated in culture medium (95\% DMEM, 5\% FBS) for $24 \mathrm{~h}$. After that, the culture medium was refreshed and supplemented with either 3-chloro-1,2-dihydroxypropane (CDP) or oxamate to the final concentration in a range from 0.1 to $100 \mathrm{mM}$. After either 24- or 48-h incubation, the media were exchanged to culture medium supplemented with MTT and the cells were incubated for additional $5 \mathrm{~h}$. Subsequently, generated formazan was dissolved by adding $100 \mu \mathrm{l}$ of $10 \%$ SDS in each well and the values of absorbance at $540 \mathrm{~nm}$ were measured by Synergy H4 microplate reader (Bio Tek, USA). The aver- age value of absorbance obtained for group of control cells corresponded to $100 \%$ survival.

To test the capability of pyruvate, citrate, 2-oxoglutarate, malate and oxalacetate to revert the cytotoxic effect of CDP, the cells were incubated in culture media supplemented with $50 \mathrm{mmol} / \mathrm{l} \mathrm{CDP}$ in combination with one of the tested compounds for $24 \mathrm{~h}$.

\section{Statistical analysis}

The results are presented as mean \pm SEM of at least three independent experiments. One-way analysis of variance with post hoc comparisons by Student-Newman-Keuls test was carried out to test for differences among the tested groups. Differences between data sets were considered statistically significant if the corresponding $p$ values were lower than 0.05 . The statistical analysis was performed with the software InStat (GraphPad Software, USA).

\section{Results}

\section{Immunoblotting analysis of $P C$ expression}

Based on the knowledge, that PC is expressed in cultured astrocytes (Cesar and Hamprecht 1995; Murín et al. 2009; Izquierdo-Garcia et al. 2014), we used the protein lysates from the cultured human astrocytes as the positive control to test the specificity of the rabbit anti-PC serum. The Western blot analysis revealed the appearance of a single band in the lane of separated proteins of the lysate prepared from cultured human astrocytes (Fig. 1, lane NHA). The estimated relative molecular mass of the visualized band
A

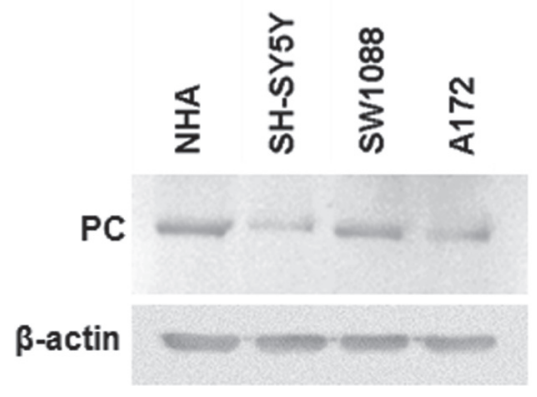

B

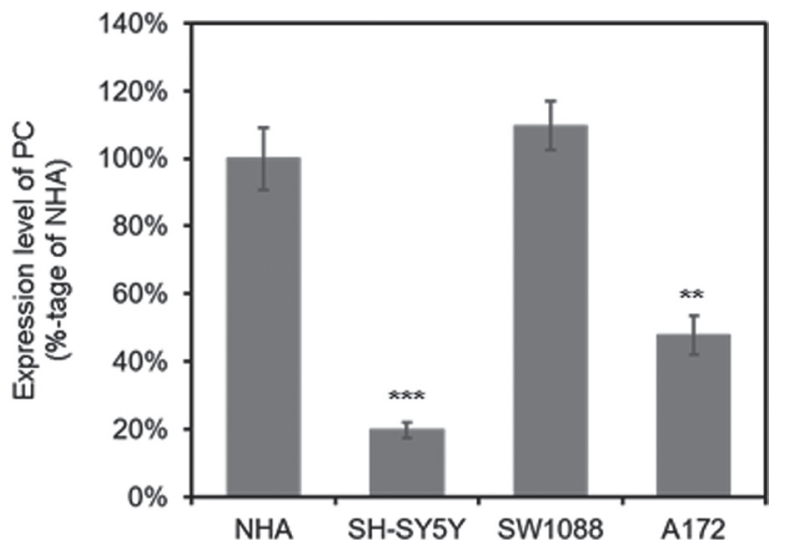

Figure 1. The immunoblotting analysis of the pyruvate carboxylase (PC) expression in cultured human astrocytes (NHA), neuroblastoma (SH-SY5Y), astrocytoma (SW1088), and glioblastoma (A1172) cells. A. The presence of PC among the proteins in cell lysates was estimated by Western blot analysis. B. The relative expression levels of PC in different cell types were determined by densitometry, using the $\beta$-actin as an internal standard. Relative expression levels of the proteins are represented as mean \pm SEM. ${ }^{* *} p<0.01,{ }^{* *} p<0.001$. 
is in the range of $122-127 \mathrm{kDa}$, which corresponds to the theoretical molecular mass of PC (Jitrapakdee et al. 2008). The appearance of the apparently same signal also among the proteins in the lysates prepared from the cultured neuroblastoma (SH-SY5Y), astrocytoma (SW 1088) and glioblastoma (A 172) cells (Fig. 1A) indicates the expression of PC in these cell types. The expression of PC among the used types of cell lines was normalized to chemiluminescent signal of $\beta$-actin (Fig. 1A) and quantified (Fig. 1B). The results of the relative quantification of $\mathrm{PC}$ expression indicate that the human astrocytoma cells express $\mathrm{PC}$ in a comparative amount to cultured human astrocytes, while the presence of PC in neuroblastoma or glioblastoma cells is decreased to $20 \pm 2 \%$ or $48 \pm 6 \%$, respectively, in comparison to astrocytes.

Furthermore, the capability of the serum to recognize only the one prominent protein in lysates prepared from cultured human cells implies also its specificity (Cesar and Hamprecht 1995; Murín et al. 2009).

\section{Immunocytochemical detection of PC expression}

The rabbit anti-PC serum was subsequently employed to identify the proportion of the human astrocytoma, glioblastoma and neuroblastoma cell expressing PC by an indirect immunochemical method. The pyruvate carboxylase in cells was visualized by rabbit anti-PC serum followed by affinitypurified anti-rabbit IgG coupled with the Alexa Fluor 488. Fluorescence microscopy revealed the appearance of the green fluorescent signal in SH-SY5Y neuroblastoma (Fig. 2A), SW1088 astrocytoma (Fig. 3A), as well as A-172 glioblastoma (Fig. 4A) cells. The green fluorescent signal was present in all observed cells, with the dotty-like appearance and localized around the cell nuclei, which were counterstained with DAPI (Figs. 2C, 3C, 4C). Such appearance of the fluorescent signal with its increased perinuclear density resembles the mitochondrial localization of PC (Murín et al. 2009). Indeed, colocalization of the red immunofluorescent signal, representing the mitochondrial specific enzymatic complex of pyruvate dehydrogenase (Figs. 2B, 3B, 4B), with the $\mathrm{PC}$ in the same subcellular compartment could be confirmed by the yellow appearance of the merged views (Figs. 2D, 3D, 4D).

Based on the observations that immunofluorescent signal was i) visible only when a combination of primary and secondary antibodies was applied for immunocytochemical staining; ii) absent from the cells treated only the mixture of secondary antibodies (Figs. $3 \mathrm{Ac}, \mathrm{Bc}, \mathrm{Cc}, \mathrm{Dc}$ ); it may be assumed that the observed fluorescence signal specifically corresponds to the presence of PC in the cells.

\section{The effect of PC inhibitors on the survival of astrocytoma cells}

To evaluate the role of PC in sustaining the growth and viability of astrocytoma cells we added oxamate or CDP into the culture media ( $90 \%$ DMEM, 10\% FBS) comprising
A
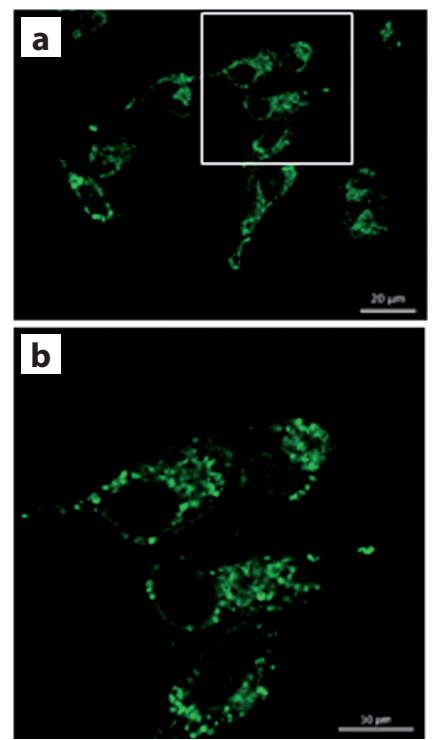

B
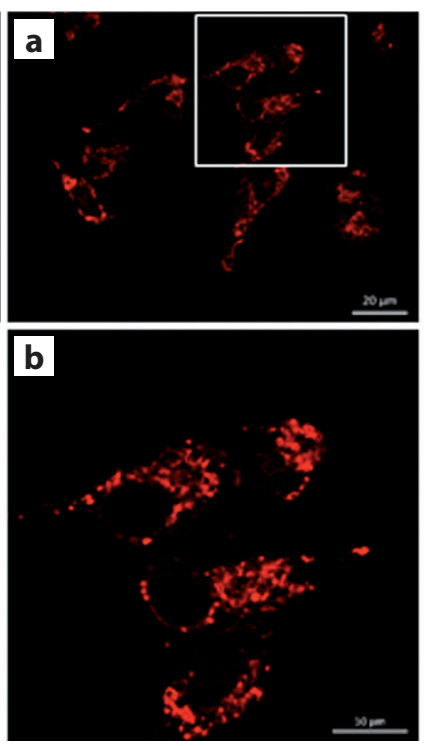

C
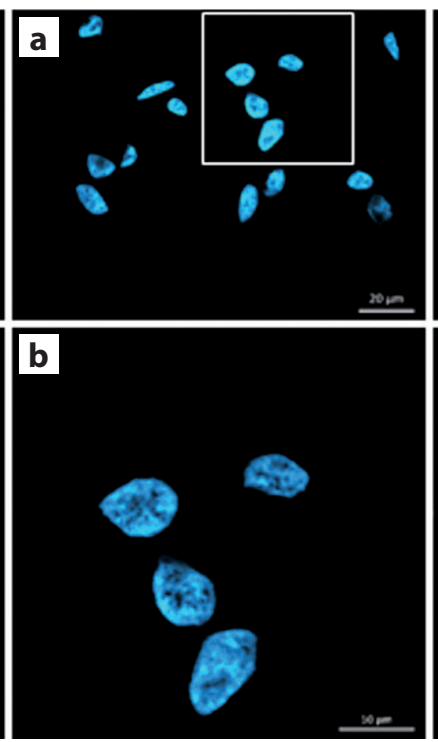

D
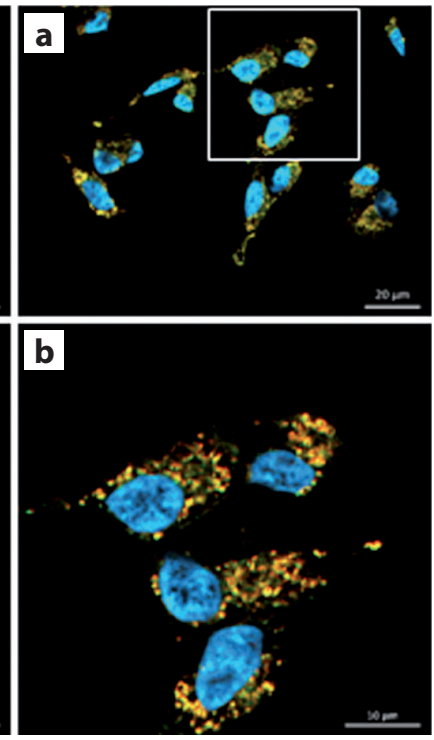

Figure 2. Immunofluorescent double labelling of the PC (A) and pyruvate dehydrogenase (B) in cells of the human neuroblastoma cell line SH-SY5Y. C. The cell nuclei were visualized by DAPI. The photomicrographs (bottom panel, b) represent the magnification of the selected areas in top panel (a). The merged views of the frames (Aa, Ba, Ca) or ( $\mathrm{Ab}, \mathrm{Bb}, \mathrm{Cb}$ ) are presented in $\mathrm{Da}$ or $\mathrm{Db}$, respectively. The scale bars in top frames (a) represent $20 \mu \mathrm{m}$ and in bottom frames (b) represent $10 \mu \mathrm{m}$. 
A
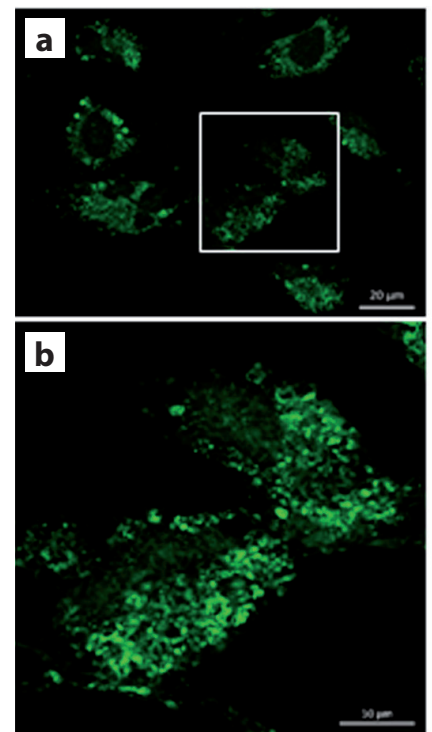

\section{c}

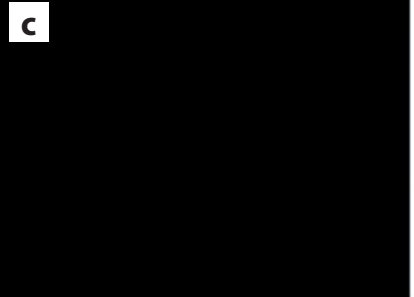

B
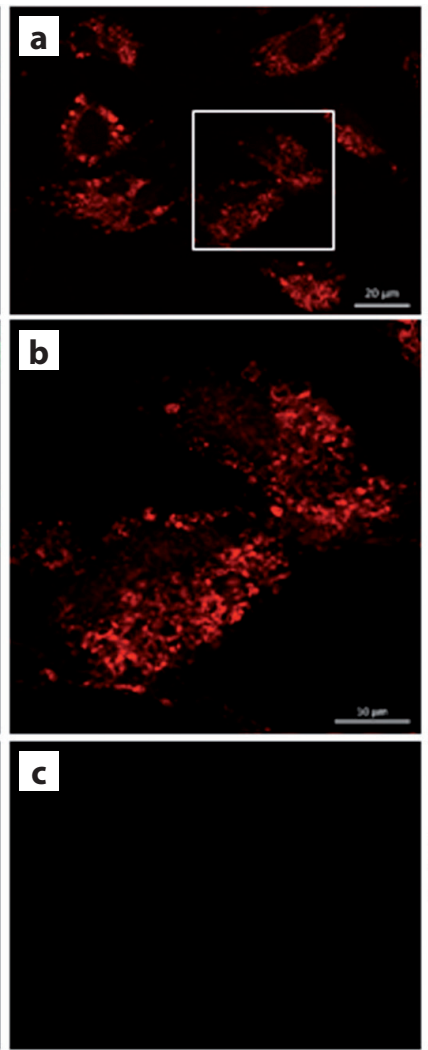

c
C
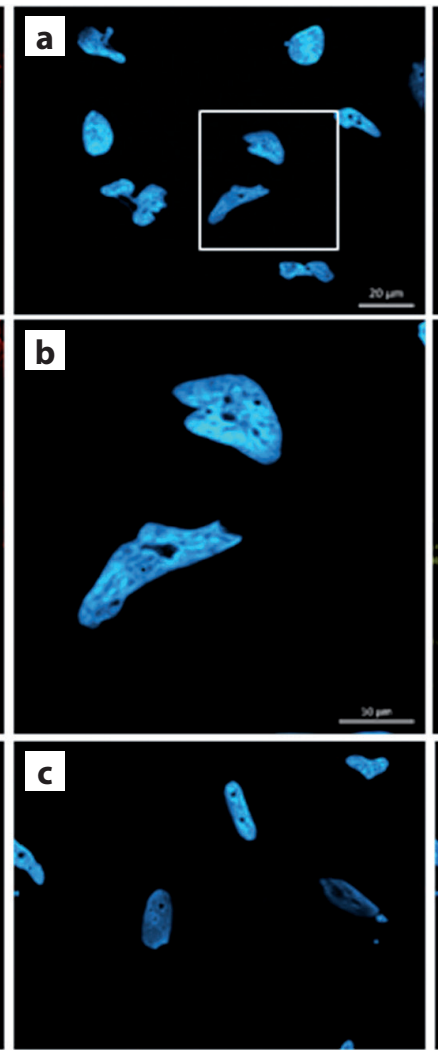

D
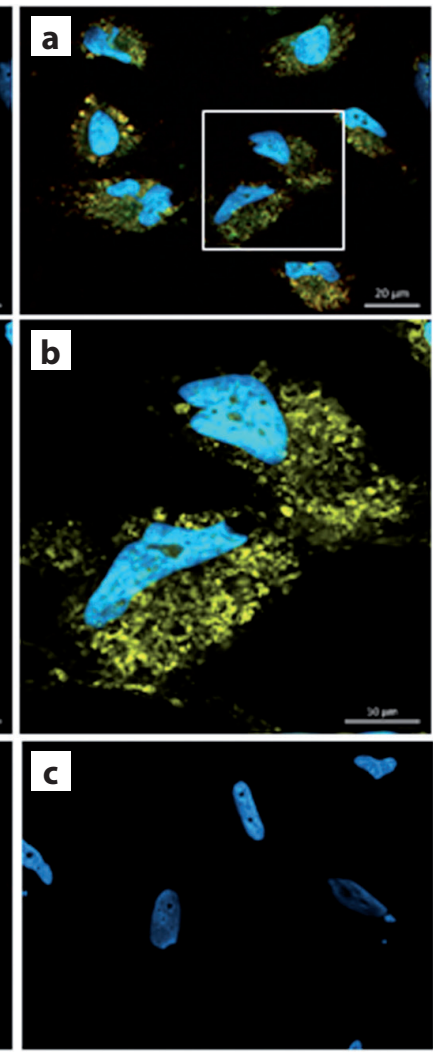

Figure 3. Immunocytofluorescent double labelling of the PC (A) and pyruvate dehydrogenase (B) in cells of the human astrocytoma cell line SW1088. The cell nuclei were visualized by DAPI (C). The photomicrographs in middle panel (b) represent the magnification of the selected areas in top panel (a). The merged views of the frames $(\mathrm{Aa}, \mathrm{Ba}, \mathrm{Ca})$ or $(\mathrm{Ab}, \mathrm{Bb}, \mathrm{Cb})$ or $(\mathrm{Ac}, \mathrm{Bc}, \mathrm{Cc})$ are presented in $(\mathbf{D a})$ or $(\mathbf{D b})$ or $(\mathbf{D c})$, respectively. The negative controls were performed by omitting the primary antibodies against PC (Ac) and pyruvate dehydrogenase (Bc). The scale bars in top (a) and botton frames (c) represent $20 \mu \mathrm{m}$ and in middle frames (b) represent $10 \mu \mathrm{m}$.

$4 \mathrm{mmol} / \mathrm{l}$ glutamine. The both compounds, oxamate and CDP, are considered to inhibit the enzymatic activity of PC (Zeczycki et al. 2010). Their effect on the cellular viability was estimated by MTT test after incubation in presence of PC inhibitor for either 24 or $48 \mathrm{~h}$ (Fig. 5A). The results of MTT test revealed that the both PC inhibitors have capability to influence the cellular viability. CDP decreased cell viability more profoundly than oxamate and the presence of CDP in culture media at the level of $50 \mathrm{mmol} / \mathrm{l}$ after 24-h incubation suppressed the viability of the cells to approximately $30 \%$ in comparison with the control group and at the level $100 \mathrm{mmol} / \mathrm{l}$ initiated the death of all cells. The cytotoxic effect of CDP was more intense if the cells were incubated for $48 \mathrm{~h}$. In such case, the viability of the cells was below $3 \%$ in media supplemented with CDP at the level $10 \mathrm{mmol} / \mathrm{l}$ or higher.

In the next step, we investigated the capability of pyruvate, 2-oxoglutarate, malate and citrate to revert the cytotoxic effect of CDP. The cells were incubated in culture media supplemented with $50 \mathrm{mmol} / \mathrm{l} \mathrm{CDP}$ and one of the tested compounds in three different levels, either 1,5 or $10 \mathrm{mmol} / \mathrm{l}$. The MTT test was performed to assess the viability of the cells after incubation for $24 \mathrm{~h}$. Only the supplementation of the media with $10 \mathrm{mmol} / \mathrm{l}$ level of either citrate, or 2-oxoglutarate, or malate partially reverted the cytotoxic effect of CDP (Fig. 5B). Pyruvate supplementation into the media at any of the tested levels had no protective outcome against the cytotoxic effect of CDP (data not shown).

\section{Discussion}

Here we provide the evidence that PC is present in cultured human astrocytoma, glioblastoma and neuroblastoma cells. These results provide the novel knowledge about the expression of PC in astrocytoma and neuroblastoma cells and 
A
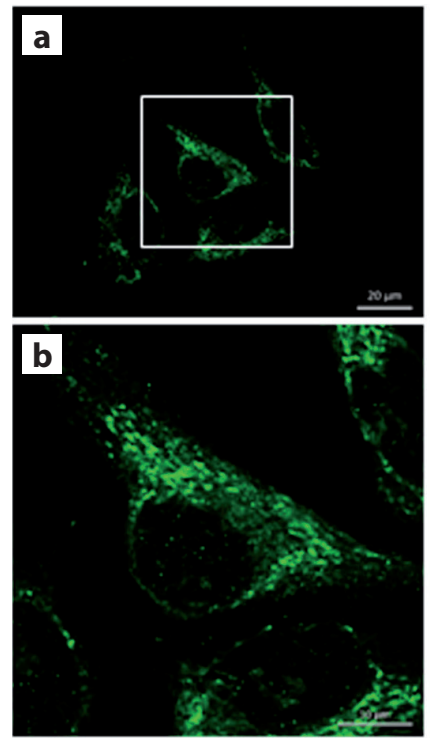

B
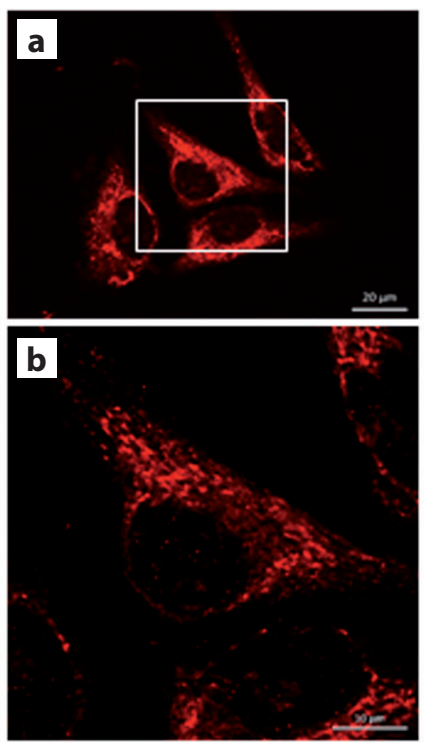

C
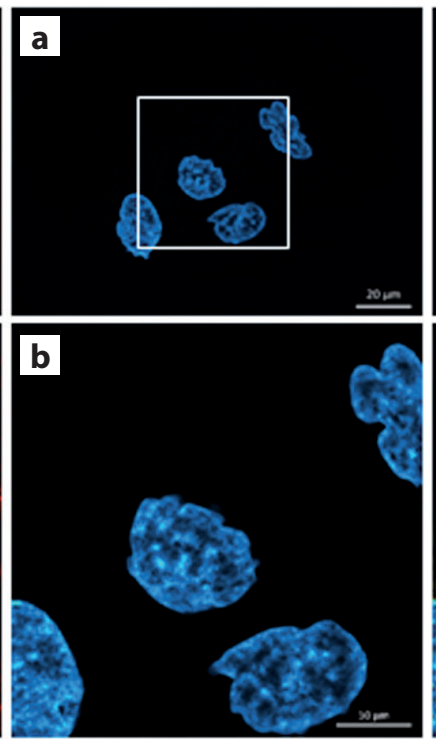

D
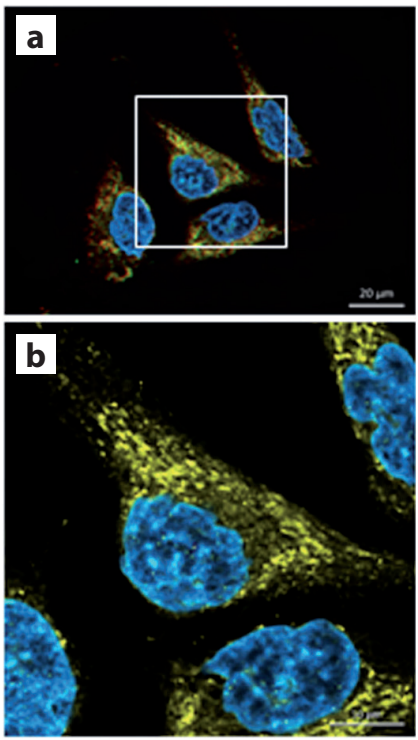

Figure 4. Immunocytofluorescent double labelling of the PC (A) and pyruvate dehydrogenase (B) in cells of the human glioblastoma cell line A172. The cell nuclei were visualized by DAPI (C). The photomicrographs in middle panel (b) represent the magnification of the selected areas in top panel (a). The merged views of the frames ( $\mathrm{Aa}, \mathrm{Ba}, \mathrm{Ca})$ or $(\mathrm{Ab}, \mathrm{Bb}, \mathrm{Cb}$ ) are presented in $\mathrm{Da}$ or $\mathrm{Db}$, respectively. The scale bars in top frames (a) represent $20 \mu \mathrm{m}$ and in bottom frames (b) represent $10 \mu \mathrm{m}$.

confirm already documented expression of PC in human glioblastoma cells (Cheng et al. 2011; Izquierdo-Garcia et al. 2014). Furthermore, we provide the data, which strongly suggests the importance of enzymatically active PC for sustaining the viability of astrocytoma cells.

$\mathrm{PC}$ is a mitochondrial enzyme with a glia specific expression among the neural cells (Shank et al. 1985; Cesar and Hamprecht 1995; Murín et al. 2009), including astrocytes. Since, astrocytes are considered to be a precursors cells of astrocytoma, it might be deduce that the observed expression of PC in astrocytoma cells is maintained during the process of tumorigenic transformation of astrocytes. The cancer cells possess the capability to alter the expression and activity of PC (Phannasil et al. 2015; Oppermann et al. 2016), and therefore, the described presence of PC in neuroblastoma cells, in contrast to neurons, could be a consequence of changes in the gene expression underlying the metabolic transformation of cells during carcinogenesis (Rodríguez-Enríquez et al. 2019) and an metabolic adaptation of neuroblastoma cells to meet their metabolic needs.
A

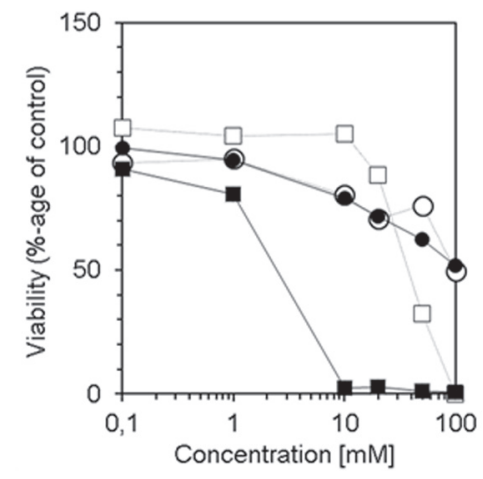

B

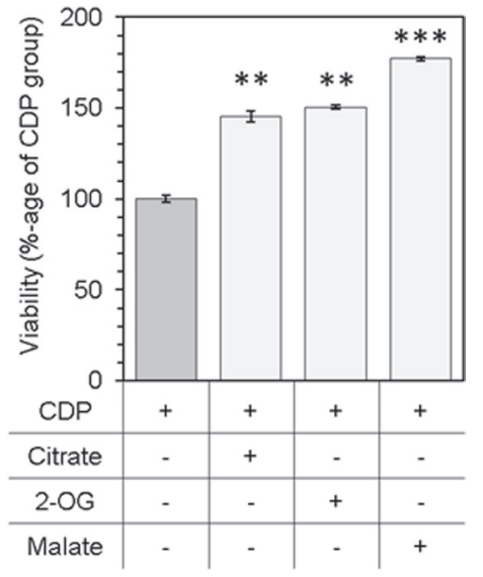

Figure 5. The effect of oxamate or CDP on viability of human astrocytoma cells (SW1088) assessed by MTT-test. A. The cells were incubated in culture media supplemented with either oxamate $(O, \bullet)$ or $\operatorname{CDP}(\square, \boldsymbol{\square})$ for either $24(\mathrm{O}, \square)$ or $48(\bullet, \square)$ hours prior the MTT-test. B. The potential of citrate $(10 \mathrm{mM})$, 2-oxoglutarate $(10 \mathrm{mM})$ or malate $(10 \mathrm{mM})$ to reverse the cytotoxic effect of $50 \mathrm{mmol} / \mathrm{l}$ CDP was estimated by MTT-test after 24-hour incubation of the cells in media supplemented with CDP and either of tested compound. ${ }^{\star *} p<0.01,{ }^{* * *} p<0.001$. 
PC catalyzes the ATP-dependent synthesis of oxaloacetate from pyruvate and $\mathrm{CO}_{2}$. Oxaloacetate is a compound that enters several distinct metabolic pathways with the suggested roles in biosynthetic and energetic metabolism. The cellular metabolism of oxaloacetate includes either i) its direct transamination to aspartate, which might be subsequently amidated to asparagine; or ii) its entry into the CAC. The both biosynthetic reactions of aspartate and asparagine require the presence of appropriate amino group donor, which in case of cancer cells is considered glutamine (Zhang et al. 2017; Jiang et al. 2019). The both, aspartate and asparagine, are amino acids those could serve several roles in cellular metabolism such as the monomers for proteosynthesis or as the indispensable substrates for nucleotide synthesis (Lieu et al. 2020). Furthermore, oxaloacetate and aspartate are intermediates of malate-aspartate electron shuttle between cytosol and mitochondrial matrix.

The cancer cells might employ two strategies to refurnish the intermediates of the CAC. Either by importing them from their milieu or by synthesis from the available substrates and intermediates of cellular metabolism (Pavlova and Thompson 2016). The import of the CAC intermediates from the extracellular space might be limited by their availability in the microenvironment and cellular transporting capacity (Elia and Fendt 2016; Muir et al. 2018). Therefore, the capability of the cells to resynthesize CAC intermediates also from endogenously generated substrates, such as pyruvate, might compensate the shortage of CAC intermediates withdrawn for biosynthetic reactions (Davidson et al. 2016) more independently on the composition of their microenvironment. Indeed, cancer cells are considered to metabolize in addition to glucose also substantial amounts of glutamine (Altman et al. 2016; Cluntun et al. 2017). Even glutamine might significantly contribute to the anaplerotic metabolism of cancer cells (DeBerardinis et al. 2008; Zhang et al. 2017), its shortage in cell milieu stimulates the adaptation of cancer cells to anaplerosis catalyzed by PC (Cheng et al. 2011). Furthermore, the enzymatically active PC was showed to be critical for survival and proliferation of non-small-cell lung cancer cells (Sellers et al. 2015) as well as glioblastoma cells in a glutamine-independent manner (Cheng et al. 2011).

The expression of PC in cultured cancer cells might reflect the importance of PC for sustaining their cellular metabolism (Jitrapakdee et al. 2008). Among the tested cells, astrocytoma cells show the highest expression level of PC (Fig. 1). Therefore, to estimate the importance of PC for survival and/or growth of human brain cancer cells, the test for the viability of astrocytoma cells in presence of oxamate or CDP was performed. We observed, that the viability of astrocytoma cells is more profoundly compromised in presence of CDP in culture media (Fig. 5A). Even both compounds, oxamate and CDP, are considered to inhibit the enzymatic activ- ity of PC (Zeczycki et al. 2010), they might also influence other cellular processes. Oxamate is a structural analogue of pyruvate, and in addition to its role of a non-competitive inhibitor of PC, competitively inhibits the entry of pyruvate into mitochondria (Martin-Requero et al. 1986) as well as it could inhibit two additional enzymes, lactate dehydrogenase (Zhai et al. 2013) and aspartate transaminase (Thornburg et al. 2008). The inhibitory effect of oxamate on PC could be suppressed by the increased intracellular concentration of pyruvate (Martin-Requero et al. 1986), which concentration might be raised by the concurrent inhibitory effect of oxamate on lactate dehydrogenase activity. CDP is a non-genotoxic carcinogen (Robjohns et al. 2003) with antifertility activity in males (Lynch et al. 1998), which could cross the blood-brain barrier (Edwards et al. 1975). In cells, CDP could be further metabolized to compounds that also inhibit the fixation of carbon dioxide by PC (Doedens and Ashmore 1972). The differences among cytotoxic potential of the oxamate and $\mathrm{CDP}$ on the astrocytoma cells could be related to diverse molecular properties of oxamate and CDP. Since, the supplementation of culture media with either citrate or malate or 2-oxoglutarate, which are intermediates of CAC, but not with pyruvate, could partially revert the cytotoxic effect of $\mathrm{CDP}$ on astrocytoma cells, we assume that the anaplerotic function of PC is obligatory for sustaining the viability of astrocytoma cells.

In summary, we can conclude, that the results of our experiments provide evidence that PC is present in cultured human astrocytoma, glioblastoma and neuroblastoma cells. In the case of astrocytoma cells, the anaplerotic activity of $\mathrm{PC}$ is fundamental for sustaining their viability even in presence of glutamine. This knowledge might be useful in better understanding of the importance of anaplerosis facilitated by PC for sustaining or even promoting the cellular metabolism of these cells, as well as its importance in maintaining or even stimulating their growth and division. Besides, the knowledge about the distribution of PC in those brain-derived cancer cell types might provide the opportunity for further detail studies on the importance of PC in cancer cell metabolism or for development or testing of the novel diagnostic tools and anticancer therapeutic interventions.

Acknowledgement. The authors are very grateful to Prof. Bernd Hamprecht (University of Tuebingen, Germany) for the generous gift of anti-PC and anti-PDH sera. This work was supported by projects: VEGA 1/0255/20, APVV-18-0088, Ministry of Health of the Slovak Republic 2018/13-UKMT-9 and by "Center of Excellence for Research in Personalized Therapy (CEVYPET)", ITMS: 26220120053 supported by the Operational Programme Research and Innovation funded by the ERDF.

Conflicts of interest. The authors declare that they have no competing interests. 


\section{References}

Altman BJ, Stine ZE, Dang CV (2016): From Krebs to clinic: glutamine metabolism to cancer therapy. Nat. Rev. Cancer. 16, 619-634 https://doi.org/10.1038/nrc.2016.71

Caneba CA, Bellance N, Yang L, Pabst L, Nagrath D (2012) Pyruvate uptake is increased in highly invasive ovarian cancer cells under anoikis conditions for anaplerosis, mitochondrial function, and migration. Am. J. Physiol. Endocrinol. Metab. 303, E1036-E1052 https://doi.org/10.1152/ajpendo.00151.2012

Cesar M, Hamprecht B (1995): Immunocytochemical examination of neural rat and mouse primary cultures using monoclonal antibodies raised against pyruvate carboxylase. J. Neurochem. $\mathbf{6 4}, 2312-2318$ https://doi.org/10.1046/j.1471-4159.1995.64052312.x

Cheng T, Sudderth J, Yang C, Mullen AR, Jin ES, Matés JM, DeBerardinis RJ (2011): Pyruvate carboxylase is required for glutamine-independent growth of tumor cells. Proc. Natl. Acad. Sci. USA 108, 8674-8679 https://doi.org/10.1073/pnas.1016627108

Christen S, Lorendeau D, Schmieder R, Broekaert D, Metzger K, Veys K, Elia I, Buescher JM, Orth MF, Davidson SM, et al. (2016): Breast cancer-derived lung metastases show increased pyruvate carboxylase-dependent anaplerosis. Cell Rep. 17, 837-848 https://doi.org/10.1016/j.celrep.2016.09.042

Cluntun AA, Lukey MJ, Cerione RA, Locasale JW (2017): Glutamine metabolism in cancer: understanding the heterogeneity. Trends Cancer 3, 169-180 https://doi.org/10.1016/j.trecan.2017.01.005

Danhier P, Bański P, Payen VL, Grasso D, Ippolito L, Sonveaux P, Porporato PE (2017): Cancer metabolism in space and time: Beyond the Warburg effect. Biochim. Biophys. Acta Bioenerg. 1858, 556-572 https://doi.org/10.1016/j.bbabio.2017.02.001

Davidson SM, Papagiannakopoulos T, Olenchock BA, Heyman JE, Keibler MA, Luengo A, Bauer MR, Jha AK, O'Brien JP, Pierce KA, et al. (2016): Environment impacts the metabolic dependencies of ras-driven non-small cell lung cancer. Cell Metab. 23, 517-528 https://doi.org/10.1016/j.cmet.2016.01.007

DeBerardinis RJ, Lum JJ, Hatzivassiliou G, Thompson CB (2008): The biology of cancer: metabolic reprogramming fuels cell growth and proliferation. Cell Metab. 7, 11-20 https://doi.org/10.1016/j.cmet.2007.10.002

Doedens D, Ashmore J (1972): Inhibition of pyruvate carboxylase by chloropyruvic acid and related compounds. Biochem. Pharmacol. 21, 1745-1751 https://doi.org/10.1016/0006-2952(72)90081-0

Edwards EM, Jones AR, Waites GM (1975): The entry of alphachlorohydrin into body fluids of male rats and its effect upon the incorporation of glycerol into lipids. J. Reprod. Fertil. 43, 225-232

Elia I, Fendt SM (2016): In vivo cancer metabolism is defined by the nutrient microenviroment. Transl. Cancer Res. 5 (Suppl. 6), S1284-S1287
Hanahan D, Weinberg RA (2000): The hallmarks of cancer. Cell $100,57-70$ https://doi.org/10.1016/S0092-8674(00)81683-9

Hanahan D, Weinberg RA (2011): Hallmarks of cancer: the next generation. Cell 144, 646-674 https://doi.org/10.1016/j.cell.2011.02.013

Izquierdo-Garcia JL, Cai LM, Chaumeil MM, Eriksson P, Robinson AE, Pieper RO, Phillips JJ, Ronen SM (2014): Glioma cells with the IDH1 mutation modulate metabolic fractional flux through pyruvate carboxylase. PLoS One 9, e108289 https://doi.org/10.1371/journal.pone.0108289

Jiang J, Srivastava S, Zhang J (2019): Starve cancer cells of glutamine: break the spell or make a hungry monster? Cancers (Basel) 11, 804

Jitrapakdee S, Vidal-Puig A, Wallace JC (2006): Anaplerotic roles of pyruvate carboxylase in mammalian tissues. Cell. Mol. Life Sci. 63, 843-854

Jitrapakdee S, St Maurice M, Rayment I, Cleland WW, Wallace JC, Attwood PV (2008) Structure, mechanism and regulation of pyruvate carboxylase. Biochem. J. 413, 369-387 https://doi.org/10.1042/BJ20080709

Lao-On U, Attwood PV, Jitrapakdee S (2018): Roles of pyruvate carboxylase in human diseases: from diabetes to cancers and infection. J. Mol. Med. (Berl.) 96, 237-247 https://doi.org/10.1007/s00109-018-1622-0

Lieu EL, Nguyen T, Rhyne S, Kim J (2020): Amino acids in cancer. Exp. Mol. Med. 52, 15-30 https://doi.org/10.1038/s12276-020-0375-3

Lin Q, He Y, Wang X, Zhang Y, Hu M, Guo W, He Y, Zhang T, Lai L, Sun Z, et al. (2020): Targeting pyruvate carboxylase by a small molecule suppresses breast cancer progression. Adv. Sci. (Weinh.) 7, 1903483 https://doi.org/10.1002/advs.201903483

Locasale JW, Cantley LC (2011): Metabolic flux and the regulation of mammalian cell growth. Cell Metab. 14, 443-451 https://doi.org/10.1016/j.cmet.2011.07.014

Lynch BS, Bryant DW, Hook GJ, Nestmann ER, Munro IC (1998): Carcinogenicity of monochloro-1,2-propanediol ( $\alpha$-chlorohydrin, 3-MCPD). International Journal of Toxicology 17, 47-76 https://doi.org/10.1080/109158198226756

Martin-Requero A, Ayuso MS, Parrilla R (1986): Rate-limiting steps for hepatic gluconeogenesis. Mechanism of oxamate inhibition of mitochondrial pyruvate metabolism. J. Biol. Chem. 261, 13973-13978

Mosmann T (1983): Rapid colorimetric assay for cellular growth and survival: application to proliferation and cytotoxicity assays. J. Immunol. Methods 65, 55-63 https://doi.org/10.1016/0022-1759(83)90303-4

Muir A, Danai LV, Vander Heiden MG (2018): Microenvironmental regulation of cancer cell metabolism: implications for experimental design and translational studies. Dis. Model. Mech. 11, dmm035758 https://doi.org/10.1242/dmm.035758

Murin R, Cesar M, Kowtharapu BS, Verleysdonk S, Hamprecht B (2009): Expression of pyruvate carboxylase in cultured oligodendroglial, microglial and ependymal cells. Neurochem. Res. 34, 480-489 https://doi.org/10.1007/s11064-008-9806-6 
Oppermann H, Ding Y, Sharma J, Berndt Paetz M, Meixensberger J, Gaunitz F, Birkemeyer C (2016): Metabolic response of glioblastoma cells associated with glucose withdrawal and pyruvate substitution as revealed by GC-MS. Nutr. Metab. (Lond.) 13, 70 https://doi.org/10.1186/s12986-016-0131-9

Owen OE, Kalhan SC, Hanson RW (2002): The key role of anaplerosis and cataplerosis for citric acid cycle function. J. Biol. Chem. 277, 30409-30412

Pate KT, Stringari C, Sprowl-Tanio S, Wang K, TeSlaa T, Hoverter NP, McQuade MM, Garner C, Digman MA, Teitell MA, et al. (2014): Wnt signaling directs a metabolic program of glycolysis and angiogenesis in colon cancer. EMBO J. 33, 1454-1473 https://doi.org/10.15252/embj.201488598

Pavlova NN, Thompson CB (2016): The emerging hallmarks of cancer metabolism. Cell Metab. 23, 27-47 https://doi.org/10.1016/j.cmet.2015.12.006

Phannasil P, Thuwajit C, Warnnissorn M, Wallace JC, MacDonald MJ, Jitrapakdee S (2015): Pyruvate carboxylase is up-regulated in breast cancer and essential to support growth and invasion of MDA-MB-231 cells. PLoS One 10, e0129848 https://doi.org/10.1371/journal.pone.0129848

Phannasil P, Ansari IH, El Azzouny M, Longacre MJ, Rattanapornsompong K, Burant CF, MacDonald MJ, Jitrapakdee S (2017): Mass spectrometry analysis shows the biosynthetic pathways supported by pyruvate carboxylase in highly invasive breast cancer cells. Biochim. Biophys. Acta Mol. Basis Dis. 1863, 537-551 https://doi.org/10.1016/j.bbadis.2016.11.021

Robjohns S, Marshall R, Fellows M, Kowalczyk G (2003): In vivo genotoxicity studies with 3-monochloropropan-1,2-diol. Mutagenesis 18, 401-404 https://doi.org/10.1093/mutage/geg017

Rodríguez-Enríquez S, Marín-Hernández Á, Gallardo-Pérez JC, Pacheco-Velázquez SC, Belmont-Díaz JA, Robledo-Cadena
DX, Vargas-Navarro JL, Corona de la Peña NA, Saavedra E, Moreno-Sánchez R (2019): Transcriptional regulation of energy metabolism in cancer cells. Cells 8, 1225 https://doi.org/10.3390/cells8101225

Sellers K, Fox MP, Bousamra M 2nd, Slone SP, Higashi RM, Miller DM, Wang Y, Yan J, Yuneva MO, Deshpande R, et al. (2015): Pyruvate carboxylase is critical for non-small-cell lung cancer proliferation. J. Clin. Invest. 125, 687-698 https://doi.org/10.1172/JCI72873

Shank RP, Bennett GS, Freytag SO, Campbell GL (1985): Pyruvate carboxylase: an astrocyte-specific enzyme implicated in the replenishment of amino acid neurotransmitter pools. Brain Res. 329, 364-367 https://doi.org/10.1016/0006-8993(85)90552-9

Thornburg JM, Nelson KK, Clem BF, Lane AN, Arumugam S, Simmons A, Eaton JW, Telang S, Chesney J (2008): Targeting aspartate aminotransferase in breast cancer. Breast Cancer Res. 10, R84 https://doi.org/10.1186/bcr2154

Zeczycki TN, Maurice MS, Attwood PV (2010): Inhibitors of pyruvate carboxylase. Open Enzym. Inhib. J. 3, 8-26 https://doi.org/10.2174/1874940201003010008

Zhai X, Yang Y, Wan J, Zhu R, Wu Y (2003): Inhibition of LDHA by oxamate induces $\mathrm{G} 2 / \mathrm{M}$ arrest, apoptosis and increases radiosensitivity in nasopharyngeal carcinoma cells. Oncol. Rep. 30, 2983-2991

Zhang J, Pavlova NN, Thompson CB (2017): Cancer cell metabolism: the essential role of the nonessential amino acid, glutamine. EMBO J. 36, 1302-1315 https://doi.org/10.15252/embj.201696151

Received: September 26, 2020

Final version accepted: January 13, 2021 